\title{
ERRATUM
}

\section{Arthropod Communities in Coffee: A Habitat Mimicking Tropical Forests}

\author{
N.E. Thyagaraj, G.V. Manjunatha Reddy, S. Onkara Naik, \\ and B. Doddabasappa
}

(C) Springer Science+Business Media Singapore 2016

A.K. Chakravarthy, S. Sridhara (eds.), Economic and Ecological Significance

of Arthropods in Diversified Ecosystems, DOI 10.1007/978-981-10-1524-3_17

\section{DOI 10.1007/978-981-10-1524-3_21}

The Figures captions in Chapter 17 were wrongly set which have now been rectified. The correct Figure captions for each Figure should reas as below:

Fig. 17.1 Female coffee berry borer (a) walking over a coffee seed (b) to show the small size of the insect (ca. $2 \mathrm{~mm}$ long, $1 \mathrm{~mm}$ wide). Female coffee berry borer boring a hole in a coffee berry (c) with characteristic symptom of infestation revealing frass on the entrance hole (d). Damage caused by larval feeding inside the coffee berry (e). Credits: (a) E. Erbe, USDA, ARS; (b) P. Greb, USDA, ARS; (c) and (e) G. Hoyos, Cenicafé; (d) G. Mercadier, USDA, ARS (Vega et al. 2009)

Fig. 17.2 Adult Phymastichus coffea (a) ovipositing in the coffee berry borer (b) with one adult parasitoid emerging from the insect (c). Adult Cephalonomia stephanoderis (d) and Aphanogmus dictynna (e), a hyperparasitoid of Prorops nasuta. Credits: (a) G. Goergen, IITA; (b) A. Castillo and F. Infante, Ecosur; (c) and (d), G. Nieto, ECOSUR; (e) M. Buffington and A. Simpkins, USDA, ARS (Vega et al. 2009)

The updated original online version for this chapter can be found at DOI 10.1007/978-981-10-1524-3_17 
Fig. 17.3 Infective juveniles of Metaparasitylenchus hypothenemi emerging from an infected coffee berry borer (left) and detail of the infective juvenile (right). Credits: (a) A. Castillo, ECOSUR; (b) G. Nieto, ECOSUR (Vega et al. 2009)

Fig. 17.4 Spiders: common predators in coffee plantations - Poecilotheria regalis

Fig. 17.5 Nest of red ants

Fig. 17.6 Coffee flowers in bloom

Fig. 17.7 (a) Coffee root grub. (b) Coffee twig showing infestation of root grub

Fig. 17.8 Shot-hole borer damage on coffee

Fig. 17.9 A nymphalid butterfly - indicator species

Fig. 17.10 A wasp nest in coffee estate

Figure captions errors in the original chapter are regretted. 